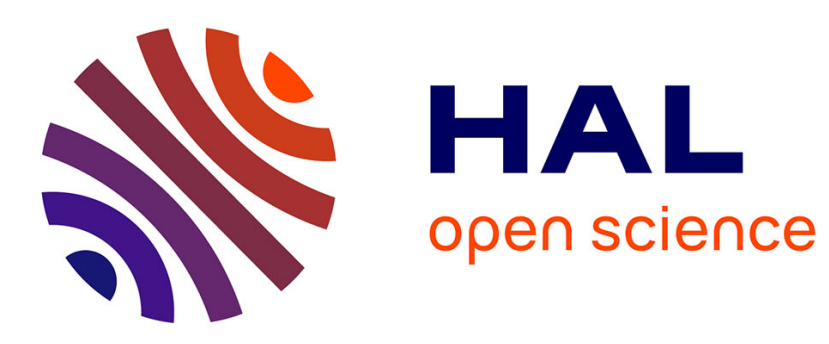

\title{
Effect of Polymer Length on the Adsorption onto Aluminogermanate Imogolite Nanotubes
}

Giuseppe Cavallaro, Giuseppe Lazzara, Frédéric Pignon, Leonardo Chiappisi, Erwan Paineau

\section{- To cite this version:}

Giuseppe Cavallaro, Giuseppe Lazzara, Frédéric Pignon, Leonardo Chiappisi, Erwan Paineau. Effect of Polymer Length on the Adsorption onto Aluminogermanate Imogolite Nanotubes. Langmuir, 2021, 37 (32), pp.9858-9864. 10.1021/acs.langmuir.1c01549 . hal-03365354

\section{HAL Id: hal-03365354 \\ https://hal.science/hal-03365354}

Submitted on 5 Oct 2021

HAL is a multi-disciplinary open access archive for the deposit and dissemination of scientific research documents, whether they are published or not. The documents may come from teaching and research institutions in France or abroad, or from public or private research centers.
L'archive ouverte pluridisciplinaire HAL, est destinée au dépôt et à la diffusion de documents scientifiques de niveau recherche, publiés ou non, émanant des établissements d'enseignement et de recherche français ou étrangers, des laboratoires publics ou privés. 


\section{Effect of Polymer Length on the Adsorption onto}

\section{Aluminogermanate Imogolite Nanotubes}

3 Giuseppe Cavallaro, ${ }^{\dagger}$ Giuseppe Lazzara, ${ }^{*},{ }^{\dagger}$ Frédéric Pignon, ${ }^{+}$Leonardo Chiappisi, ${ }^{\square}$ Erwan

$5 \quad$ 'Department of Physics and Chemistry, University of Palermo, Viale delle Scienze, pad. 17,

$6 \quad$ Palermo 90128, Italy

$7 \quad$ Laboratoire de Rhéologie et Procédés, Univ. Grenoble Alpes, CNRS, Grenoble INP (Institut

8 of Engineering Univ. Grenoble-Alpes), F-38000 Grenoble, France

$9 \square^{\square}$ Institut Laue-Langevin, BP 156, 38042 Grenoble, France

$10{ }^{\S}$ Université Paris-Saclay, CNRS, Laboratoire de Physique des Solides, 91405, Orsay, France

11

12 E-mails: giuseppe.lazzara@ unipa.it; erwan-nicolas.paineau@ universite-paris-saclay.fr. 


\section{ABSTRACT.}

15 This study evidences the adsorption of model non-ionic polymers onto aluminogermanate 16 imogolite nanotubes, an attractive porous nanofiller with potential molecular loading and 17 release applications. We resolve the underlying mechanisms between nanotubes and 18 polyethylene glycols with different molecular weight by means of nano-isothermal titration

19 calorimetry. The analysis of the results provides a direct thermodynamic characterization, 20 allowing to propose a detailed description of the energetics involved in the formation of 21 polymer/imogolite complexes. The affinity towards the nanotube surface is enthalpy-driven 22 and strongly depends on the polymer chain length, which significantly affects the polymer 23 configuration and the flow properties of the resulting complexes, probed by small-angle 24 neutron scattering and rheology, respectively. These findings open new avenues for the 25 rational design of these hybrid mixtures for advanced applications. 


\section{INTRODUCTION}

Imogolite nanotube (INT) is an aluminosilicate clay mineral, naturally occurring and widespread in well-drained volcanic ash soils. ${ }^{1}$ Unlike halloysite, another tubular clay mineral, ${ }^{2}$ INTs can be readily synthesized through hydrothermal methods. ${ }^{3,4}$ The structure of these nanotubes is rather unique. The external walls consist of gibbsite-like sheet $\mathrm{Al}(\mathrm{OH})_{3}$ while the cavity interface is formed by isolated $\left(\mathrm{SiO}_{3}\right) \mathrm{OH}$ tetrahedron units connected upright to the octahedral vacancies by covalent bonding. ${ }^{5}$ Silicon can be replaced by germanium allowing to increase the diameter of the inner cavity from 1.5 to $3 \mathrm{~nm}$ for single-walled INTs. ${ }^{6,7}$ Furthermore, modifications of the synthesis conditions offer a convenient way for designing innovative INTs with well-defined morphologies (single or double-walled structures), ${ }^{8}$ modular interfaces (e.g. hydrophilic or hydrophobic cavities) ${ }^{9-11}$ and high colloidal stability in aqueous media. ${ }^{12-14}$ All these properties have led in recent years to a renewed interest in synthetic imogolite-type nanotubes as promising nano-reactors notably for molecular confinement ${ }^{15-18}$ or photocatalytic applications. ${ }^{19-23}$

INT offers similar characteristics to those of carbon nanotubes (CNTs) in terms of rigidity, sizes and aspect ratios while retaining transparency and self-organization in highly dilute conditions. ${ }^{24,25}$ Although they display larger band gaps than $\mathrm{CNTs},{ }^{26}$ they are cheaper to produce with monodisperse diameters without further sorting techniques. Consequently, imogolite nanotubes represent an interesting alternative of the carbon nanotubes in numerous applications including the fabrication of polymer/filler nanocomposites with multifunctional characteristics. Within this, imogolite was successfully employed with various polymers as a reinforced filler for functional nanocomposites with enhanced mechanical, optical, or electrical properties, including self-healing capability. ${ }^{27-34}$ An interesting advantage of INTs is the high density of hydroxyl groups on the outer surface $\left(\sim 18 \mathrm{OH} / \mathrm{nm}^{2}\right)$. It should promote different possibilities of polymer adsorption, ${ }^{35}$ or change in conformation as shown recently 
52 by nuclear magnetic resonance. ${ }^{36,37}$ To date, however, the underlying mechanisms remain 53 largely unexplored.

One of the most used techniques to probe the polymer-nanoclay interaction mechanism is isothermal titration calorimetry (ITC), which allows the experimentalist to determine the thermodynamic parameters for the adsorption phenomenon through direct measurements. It allowed clarifying the interactions in terms of hydrophobic/electrostatic forces and polymer degree of freedom through the evaluation of the entropic contribution. ${ }^{38,39}$ Moreover, the determination of the adsorption isotherm and the maximum amount of polymer adsorbed per mass of nanoclay in comparison with the polymer gyration radius and geometric features of the nanoparticle, provided an indirect representation on the polymer conformation at the interface. ${ }^{40}$ It should be noted that isothermal calorimetry is the only correct approach to determine the enthalpy change of a reaction if the stoichiometry may change with temperature as, in the latter case, the well-known van't Hoff approach cannot be used. ${ }^{41}$

Here, we investigated the adsorption of non-ionic polymers with variable molecular weight on the outer surface of anisometric double-walled germanium-based imogolite (GeDWINTs) with outer diameter of $4.5 \mathrm{~nm}$ and average length around $100 \mathrm{~nm}$ (Figure 1). ${ }^{14}$ Polyethylene glycols (PEGs) with variable molecular weight are selected as model hydrosoluble non-ionic polymers that are frequently added with clay minerals. ${ }^{42-44} \mathrm{We}$ proposed the first detailed description on the energetics involved in the formation of 71 polymer/imogolite complexes by combining ITC measurements with small-angle neutron 72 scattering (SANS) and rheological experiments. Determination of thermodynamic parameters 73 allowed predicting the fraction of polymer adsorbed onto the nanotubes surface. The 74 adsorption mechanism is dependent of the PEG chain length, modifying the conformation and 75 the flow properties of the resulting mixtures. 


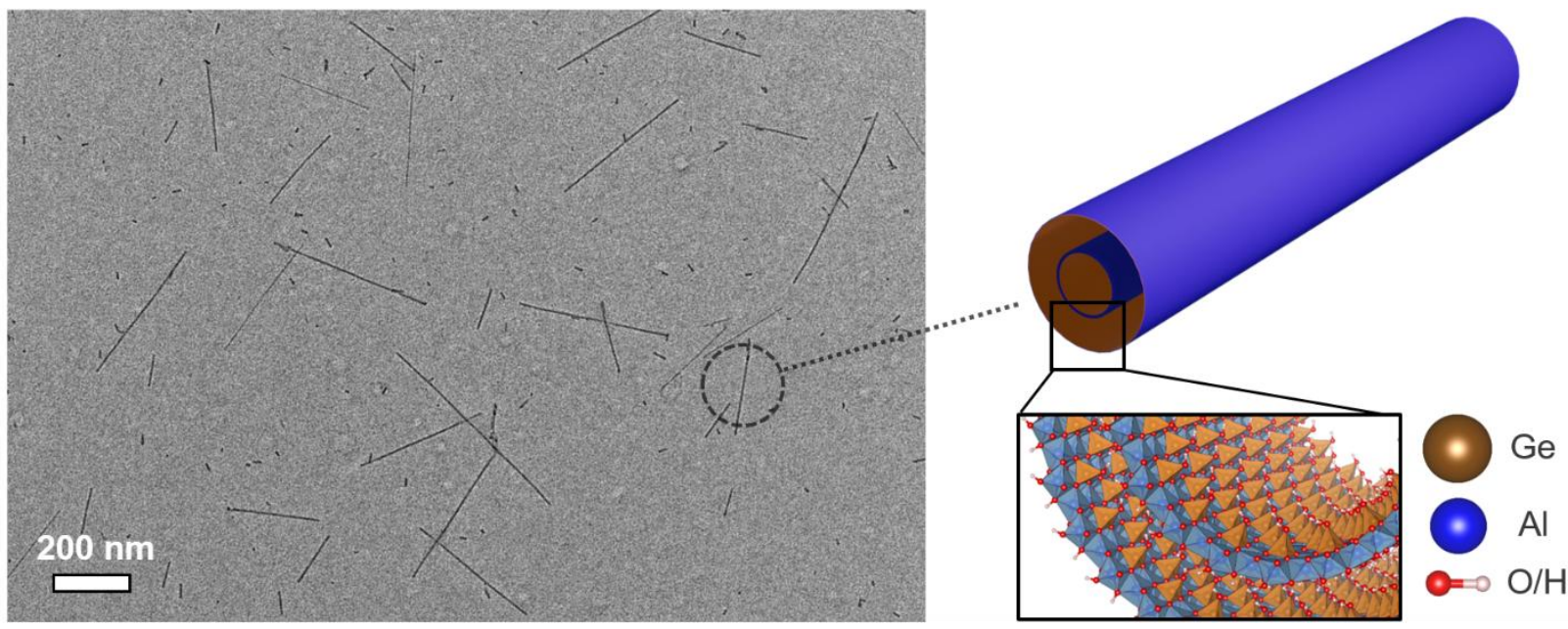

Figure 1. Representative TEM image of aluminogermanate double-walled imogolite nanotubes (Ge-DWINTs). The sketch in the right illustrates the atomic structure of a GeDWINT with the curved $\mathrm{Al}(\mathrm{OH})_{3}$ sheet (in blue) and isolated $\left(\mathrm{GeO}_{3}\right) \mathrm{OH}$ units (in orange). Oxygen and hydrogen atoms are represented in red and white, respectively.

\section{EXPERIMENTAL SECTION}

Materials. Polyethylene glycols (PEGs) with various average molecular weight $\left(\mathrm{M}_{\mathrm{w}}=200\right.$, 400, 2k, 3k and 20k g.mol ${ }^{-1}$ ), were purchased from Sigma Aldrich. Polymer solutions have been prepared by weight $( \pm 0.01 \mathrm{mg})$ and keeping under magnetic stirring overnight. Details on the synthesis and characterizations of Ge-DWINT clay nanotubes have been reported elsewhere. $^{45}$ After dialysis, as-obtained Ge-DWINTs form stable colloidal dispersions $(\mathrm{C}=$ 10 g. $\mathrm{L}^{-1}$ ), where the nanotubes are individually dispersed. ${ }^{24}$ Mixtures of Ge-DWINTs with PEGs were prepared by adding the appropriate amount of polymer at different polymer/imogolite mass ratio $\left(R_{\mathrm{P} / \mathrm{INTS}}\right)$ while keeping constant the imogolite concentration.

Isothermal Titration Calorimetry (ITC). ITC experiments were performed by using the ultrasensitive nano-ITC200 calorimeter (MicroCal). An amount of approximately $40 \mu \mathrm{L}$ of the water/polymer mixture was injected into the thermally equilibrated ITC cell $(200 \mu \mathrm{L})$ 
93 specific volume of the INTs was calculated as:

$$
v_{s p}=(1 / d)-10^{3} \frac{\left(d-d_{0}\right)}{w d d_{0}}
$$

112 being $d$ the experimental density for Ge-DWINTs dispersion at concentration $w$ (expressed as $113 \mathrm{~g}$ of Ge-DWINTs/kg of solvent) and $d_{0}$ is the water density. 
114 Rheology. Rheological measurements were performed on a controlled-stress rheometer

115 (Discovery HR-3, TA Instruments) using a cone-plate geometry (60 mm in diameter, $1^{\circ}$ in

116 angle) and a solvent trap cover to prevent sample evaporation. Flow curves of PEGs/Ge-

117 DWINTs $\left(R_{\mathrm{P} / \mathrm{INTs}}=10\right)$ were measured under a controlled shear rate from 1 to $2200 \mathrm{~s}^{-1}$.

\section{RESULTS AND DISCUSSION}

119 Thermodynamic characterization of PEG/Ge-DWINTs dispersions. The thermodynamics

120 of the polymer adsorption onto aqueous dispersions of Ge-DWINTs was investigated by ITC

121 through the stepwise injection method. The effects of dilution of the polymer and imogolite

122 were measured and subtracted from the heats of titration to obtain the thermal effects of the

123 polymer/imogolite interaction at each step. Based on the ITC data, we determined the

124 cumulative variation of enthalpy $\left(\Delta H_{i c}\right)$ at variable polymer/imogolite mass ratio $\left(R_{\mathrm{P} / \mathrm{INTs}}\right)$ for

125 PEGs with different molecular weight (Figure 2). Details for the calculation of $\Delta H_{i c}$ are

126 presented in Supporting Information. 


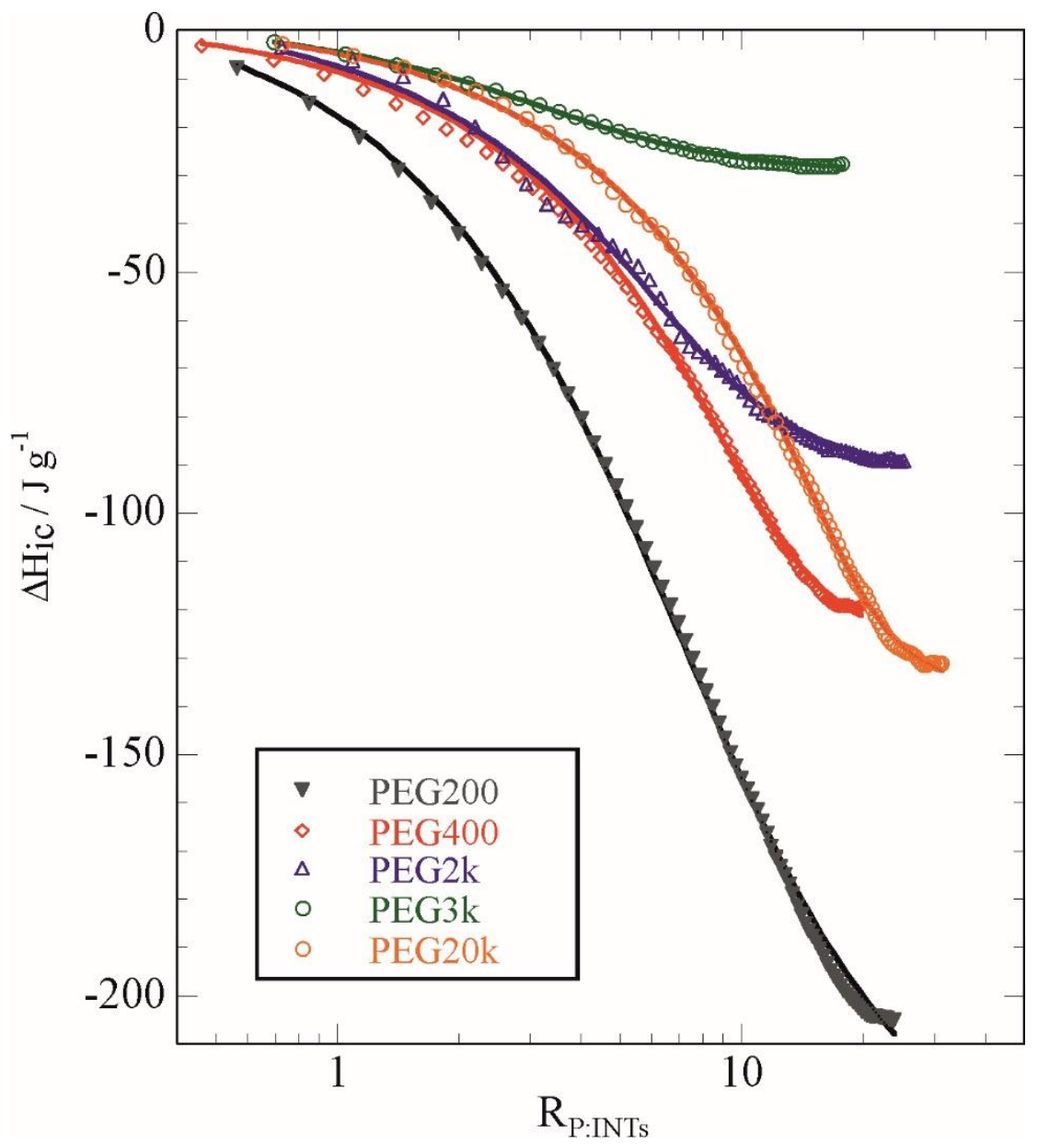

128 Figure 2. Isothermal titration data of Ge-DWINTs with PEGs of different molecular weight.

129 Lines correspond to best fits according to Langmuir adsorption model.

130 As for other polymer/clay systems, ${ }^{38,40}$ the $\Delta H_{i c}$ vs $R_{\mathrm{P} / \mathrm{INTs}}$ trends correspond to a single

131 adsorption process that were successfully described by the Langmuir adsorption model

132 (Figure 2), providing the enthalpy $\left(\Delta H_{a d s}^{0}\right)$ and the equilibrium constant $\left(K_{a d s}\right)$ for the PEGs

133 adsorption onto imogolite surfaces. According to the $K_{a d s}$ and $\Delta H^{0}$ ads values, we estimated the

134 standard free energy $\left(\Delta G_{a d s}^{\circ}\right)$ and the entropy $\left(\Delta S_{a d s}^{\circ}\right)$ for the adsorption process as:

$$
\begin{gathered}
\Delta G_{a d s}^{\circ}=-R T \ln K_{a d s} \\
T \Delta S_{a d s}^{\circ}=\Delta H_{a d s}^{\circ}-\Delta G_{a d s}^{\circ}
\end{gathered}
$$


135 In addition, the fitting of ITC data (Figure 2) allowed us to determine the PEGs/INTs

136 stoichiometry $(Z)$ at the saturation point. Namely, $Z$ represents the maximum amount of PEGs

137 moles adsorbed per gram of imogolite nanotubes. The fitting analysis of the experimental

$138 \Delta H_{i c}$ vs $R_{\mathrm{P} / \mathrm{INT}}$ functions are detailed in Supporting Information.

139 Table 1 collects the thermodynamic parameters and the stoichiometry values for the 140 adsorption of PEGs with variable molecular weights onto imogolite. 
141 Table 1. Investigated polyethylene glycol (PEG) with various molecular weight and the corresponding adsorption parameters deduced from ITC 142 measurements performed at $298 \mathrm{~K}$.

\begin{tabular}{|c|c|c|c|c|c|c|}
\hline Polymer & $\begin{array}{c}\text { Molecular } \\
\text { weight }\left(\mathrm{g} \cdot \mathrm{mol}^{-1}\right)\end{array}$ & $\begin{array}{c}\mathrm{K}_{\mathrm{ads}} \\
\left(\mathrm{dm}^{3} \mathrm{~mol}^{-1}\right)\end{array}$ & $\begin{array}{c}\mathrm{Z}^{\mathrm{a}} \\
\left(\mathrm{mmol}_{\mathrm{P}} \mathrm{g}_{\mathrm{INTs}}{ }^{-1}\right)\end{array}$ & $\begin{array}{c}\Delta \mathrm{H}_{\text {ads }}^{0} \\
\left(\mathrm{~kJ} \mathrm{~mol}^{-1}\right)\end{array}$ & $\begin{array}{c}\Delta \mathrm{G}_{\mathrm{ads}}^{0} \\
\left(\mathrm{~kJ} \mathrm{~mol}^{-1}\right)\end{array}$ & $\begin{array}{c}\Delta \mathrm{S}_{\mathrm{ads}}^{0} \\
\left(\mathrm{~kJ} \mathrm{~mol}^{-1} \mathrm{~K}^{-1}\right)\end{array}$ \\
\hline PEG200 & 200 & $(9.5 \pm 1.7) \cdot 10^{4}$ & $37 \pm 2$ & $-2.15 \pm 0.17$ & $-28.8 \pm 0.5$ & $0.088 \pm 0.007$ \\
\hline PEG400 & 400 & $(1.6 \pm 0.4) \cdot 10^{6}$ & $30.6 \pm 0.7$ & $-2.18 \pm 0.16$ & $-35.4 \pm 0.7$ & $0.115 \pm 0.004$ \\
\hline PEG2k & 2000 & $(3.3 \pm 1.7) \cdot 10^{6}$ & $2.5 \pm 0.2$ & $-9.65 \pm 1.24$ & $-37.2 \pm 1.6$ & $0.09 \pm 0.01$ \\
\hline PEG3k & 3000 & $(8.0 \pm 3.0) \cdot 10^{6}$ & $4.8 \pm 0.2$ & $-9.3 \pm 0.7$ & $-39.4 \pm 1.2$ & $0.101 \pm 0.010$ \\
\hline PEG20k & 20000 & $(1.4 \pm 0.3) \cdot 10^{8}$ & $1.00 \pm 0.02$ & $-55.5 \pm 1.6$ & $-46.5 \pm 0.7$ & $-0.030 \pm 0.001$ \\
\hline
\end{tabular}


As evidenced from Table 1, the polymer molecular weight affects both the thermodynamic parameters and the maximum mass of PEG adsorbed onto Ge-DWINTs. The equilibrium constant displays a monotonic evolution according to the PEG chain length and it is related to different affinity. As shown for clay nanosheets, a limited affinity for the clay surface was observed for PEG with low molecular weight (1000-4000 g.mol ${ }^{-1}$ ) whereas higher values resulted in an increase of the adsorbed mass of polymer in conjunction with a change of polymer conformation. ${ }^{50,51}$ The negative values of standard free energy indicate that PEG adsorption onto Ge-DWINTs surface is energetically favored. Both $\Delta G_{a d s}^{\circ}$ and $\Delta H_{a d s}^{\circ}$ decrease with PEG molecular weight, which indicates an enthalpy driven adsorption process for all the mixtures. Given that the enthalpy of adsorption per mole of polymer is always negative, PEG/imogolite interactions are the dominant forces in the adsorption process although the enthalpic contribution is much more relevant for polymers with a longer chain. As concerns $\Delta S_{a d s}^{\circ}$, we determined positive values for all the PEGs used in this work (except for PEG20k). In general, the change in entropy is related to the following contrasting effects: $(i)$ a loss of configuration freedom of the polymer in the adsorbed state, which induces a decrease of entropy $\left(\Delta S_{a d s}^{\circ}<0\right)$ or (ii) a water release from the polymer $\left(\Delta S_{a d s}^{\circ}>0\right)$. The positive entropy values highlight that de-hydration from the adsorbed PEG represents the dominant entropic factor during the adsorption. On the other hand, $\Delta S_{a d s}^{\circ}<0$ was observed for the highest molecular weight suggesting that the dehydration phenomenon is less relevant for this mixture.

The maximum amount of PEG molecules adsorbed onto the imogolite surface decreases sharply with the polymer molecular weight ( $Z$ values in Table 1$)$ and therefore the most hydrated structure is expected for PEG20k compared to the other polymers. Based on the thermodynamic parameters (Table 1), we can deduce the fraction of polymer adsorbed onto imogolite surfaces at 
variable $R_{\mathrm{P} / \mathrm{INTs}}$. Based on the fitting parameters of ITC curves (see details in Supporting Information), we calculated the fraction of adsorbed polymer onto imogolite as a function of the $R_{\mathrm{P} / \mathrm{INTs}}$ for PEG2k/INTs and PEG20k/INTs complexes (Figure 3).

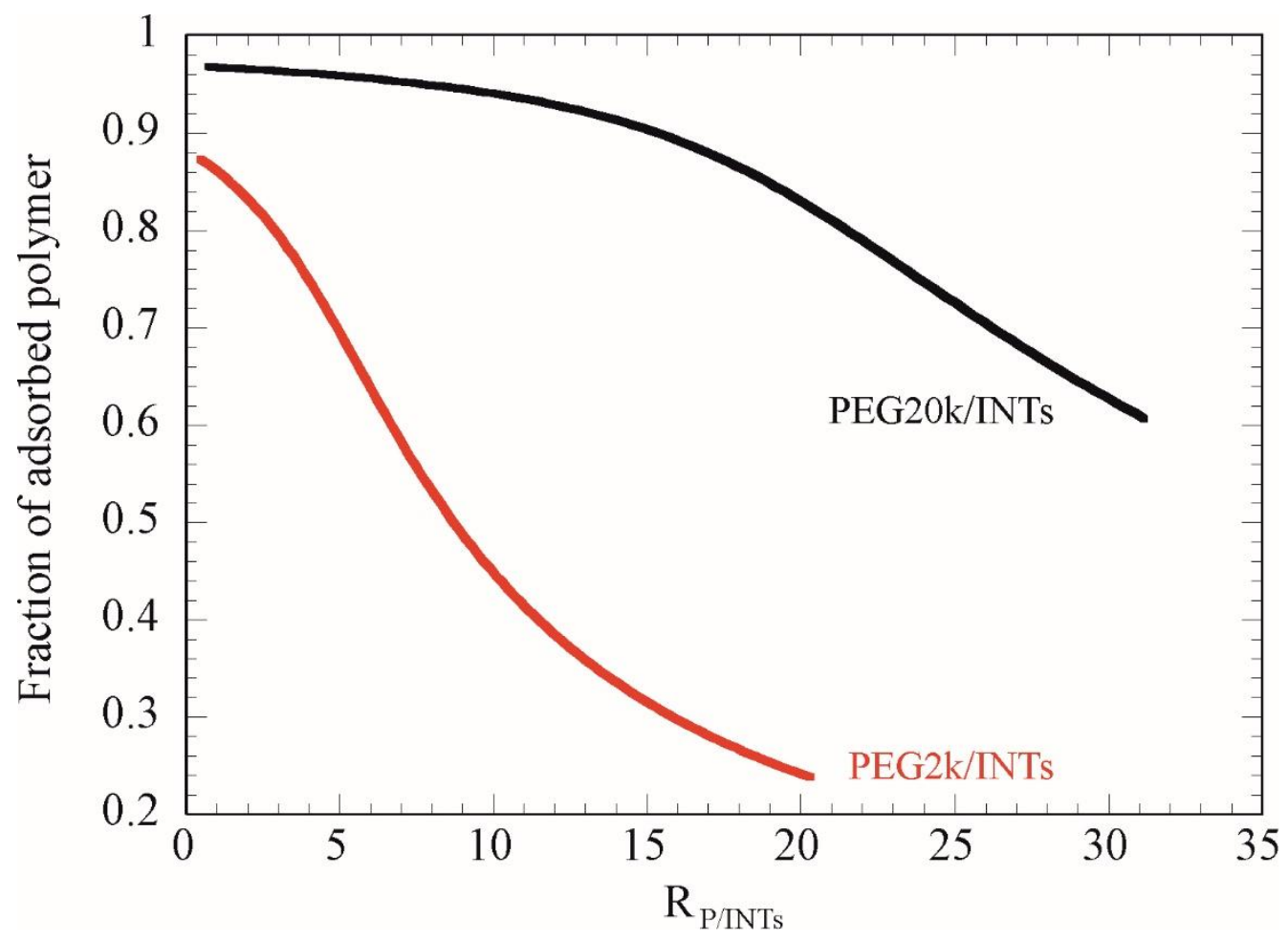

Figure 3. Calculated fraction of polymer adsorbed onto Ge-DWINTs at variable $R_{\mathrm{P} / \mathrm{INT}}$ for GeDWINTs complexes with PEG2k (red) and PEG20k (black).

Within the investigated polymer/Ge-DWINTs range, we estimated a larger adsorbed fraction for PEG with the longest chain. As example, for $R_{\mathrm{P} / \mathrm{INTs}}=10$, the fractions of polymer adsorbed onto Ge-DWINTs are ca. 0.4 and 0.95 for PEG2k and PEG20k, respectively. The different adsorption profiles are the result of the equilibrium constant, weighted by the maximum possible amount of polymer that can be allocated at the solid/liquid interface. In other words, there is more place for small polymers (expressed in total mass), but less tendency to fill that space as evidenced by the equilibrium constants. 
The dependence of the affinity toward the Ge-DWINTs surface from the PEG molecular weight was further investigated by SANS for PEG2k and PEG20k. It should be noted that the scattering from dilute Ge-DWINTs dispersions $\left(1\right.$ g.L $\left.{ }^{-1}\right)$ in the same solvent has a negligible flat scattering intensity in the investigated scattering vector regime (Figure S1). As a general feature (Figure 4), the addition of Ge-DWINTs to PEG solutions does not influence the shape of the curves. All scattering curves were analysed with a model of a Gaussian coil ${ }^{52}$ :

$$
I(q)=I_{0} \frac{2\left[\exp \left(-q^{2} R_{g}^{2}\right)+q^{2} R_{g}^{2}-1\right]}{q^{4} R_{g}^{4}}
$$

with $I_{0}$ and $R_{g}$ being the forward scattering intensity and the radius of gyration of the chain, respectively. The values are given in Table 2 . The overlap concentration was calculated from the values of the radii of gyration, as:

$$
c^{*}=\frac{M w}{(4 \pi / 3) R_{g}^{3} N_{A}}
$$

Confirming that the experiment were performed in the dilute regime, the interactions between the polymer chains can be estimated between the ratio of the determined forward scattering and the predicted value, ${ }^{53}$ calculated as:

$$
I_{0}^{\text {calc }}=\frac{\phi_{p} M w \Delta \rho^{2}}{d_{p} N_{A}}
$$

In eq. $6, \phi_{p}$ is the polymer concentration in volume fraction, $d_{\mathrm{p}}$ its density (a value of $1.199 \mathrm{~g}$ $\mathrm{cm}^{-3}$ was used $)^{54}$, and $\Delta \rho$ the scattering contrast. A ratio of 0.5 and 0.1 for PEG2k and PEG20k, respectively, between the experimental and the calculated forward scattering intensity indicates a 
significant repulsive interaction between the polymer chains, in agreement with previous studies (Table 2). ${ }^{53}$

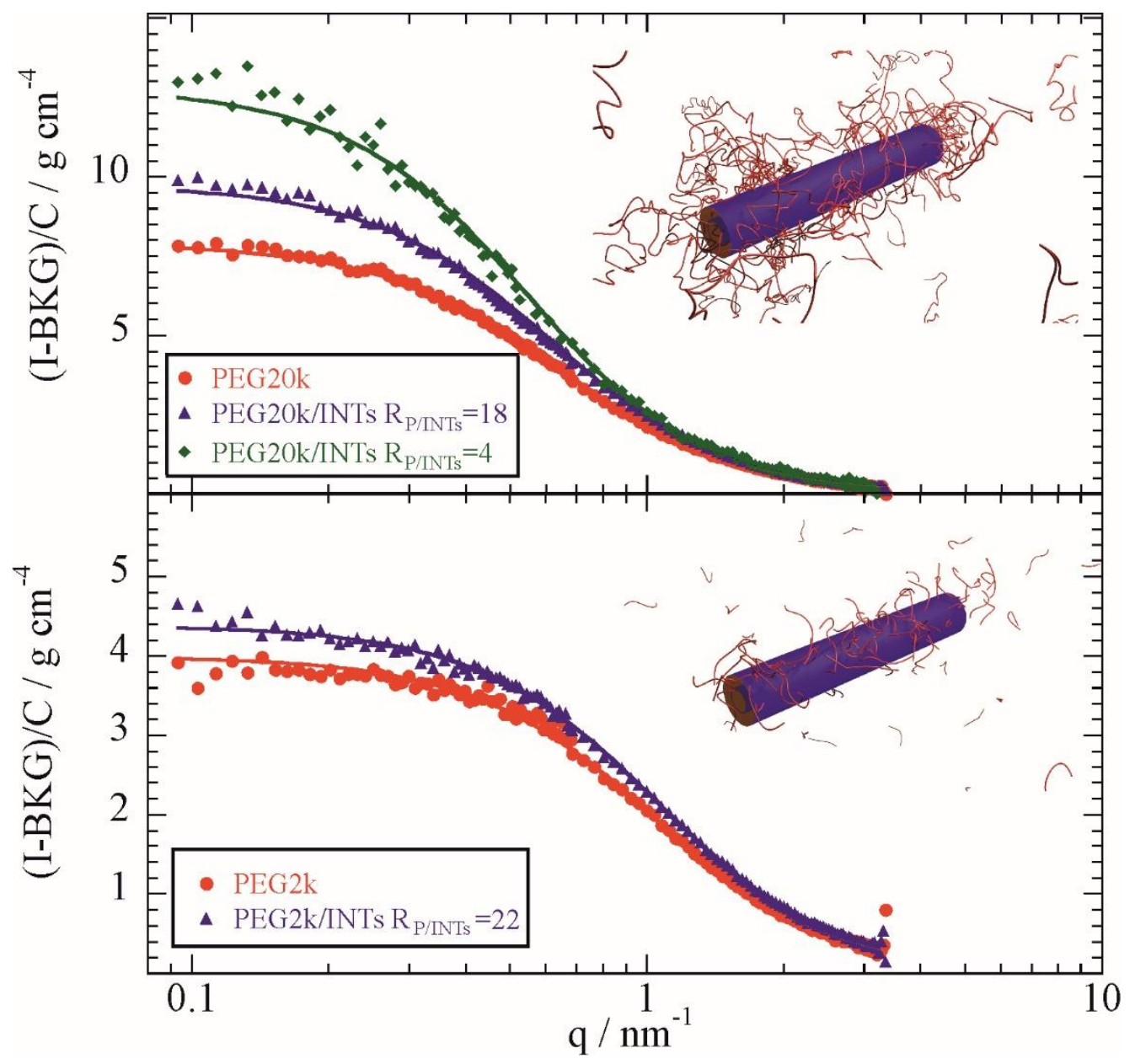

Figure 4. Neutron Scattering Intensity function after background (BKG) subtraction and polymer concentration normalization $\left(\mathrm{C}_{\mathrm{P}}\right)$ of PEGs in the presence and absence of Ge-DWINTs ( 1 g. $\mathrm{L}^{-1}$ ) at $25{ }^{\circ} \mathrm{C}$. Solvent was $\mathrm{H}_{2} \mathrm{O} / \mathrm{D}_{2} \mathrm{O}$ with a mass ratio of $1 / 10$. The continuous lines correspond to the fit of the scattering curves (see text for details). 
Table 2. Forward scattering intensity $I_{0}$ and radius of gyration $R_{g}$ deduced from the modelling of SANS curves with a Gaussian coil model.

\begin{tabular}{lccccc}
\hline \multicolumn{1}{c}{ System } & $\mathrm{R}_{\mathrm{P} / \mathrm{INT}}$ & $\begin{array}{c}I_{0}^{\text {exp }} \\
\left(\mathrm{cm}^{-1}\right)\end{array}$ & $\begin{array}{c}R_{g} \\
(\mathrm{~nm})\end{array}$ & $\begin{array}{c}I_{0}^{\text {calc }} \\
\left(\mathrm{cm}^{-1}\right)\end{array}$ & $\begin{array}{l}I_{0}^{\text {exp }} \\
I_{0}^{\text {calc }}\end{array}$ \\
\hline PEG2k & - & $0.08 \pm 0.01$ & $1.56 \pm 0.08$ & 0.16 & 0.51 \\
PEG2k/INTs & 22 & $0.10 \pm 0.02$ & $1.54 \pm 0.05$ & 0.15 & 0.62 \\
\hline PEG20k & - & $0.18 \pm 0.02$ & $2.49 \pm 0.06$ & 1.61 & 0.11 \\
PEG20/INTs & 18 & $0.17 \pm 0.02$ & $2.61 \pm 0.06$ & 1.22 & 0.14 \\
& 4 & $0.05 \pm 0.01$ & $3.02 \pm 0.08$ & 0.30 & 0.18
\end{tabular}

The analysis of the SANS data shows that the conformation of the polymer is not, or only minimally, affected by the presence of the clay nanotube, as deduced from constant value of radius of gyration obtained. In contrast, an increase in scattering intensity is observed upon addition of Ge-DWINTS to the dilute PEG solution. The origin of this increase has to be found in the attractive interaction between the nanoclay and the polymer. In fact, both the adsorption of PEG on the Ge-DWINTs and a reduced repulsion between the PEG chains in solution would result in an increase of the forward scattering intensity. The effect is more pronounced for the longer PEG chains for which the radius of gyration increases from 2.5 to $3 \mathrm{~nm}$ with decreasing $R_{\mathrm{P} / \mathrm{NTS}}($ Table 2). This slight stretching of PEG20k chains can be ascribed to a crowding phenomenon due to the larger amount of polymer adsorbed onto Ge-DWINTs predicted by the ITC experiments, ca 0.96 compared to 0.87 for $R_{\mathrm{P} / \mathrm{INTs}}=4$ and 18 , respectively. The stretching of the polymer chain is an indication of a relatively compact organization at the solid/liquid interface. This is confirmed by the grafting density of ca. 1.6 chains $\mathrm{nm}^{-2}$, estimated from $Z$ values reported in Table 1 and by using the experimental specific volume of Ge-DWINTs $\left(0.3949 \mathrm{~cm}^{3} \mathrm{~g}^{-1}\right)$ and the characteristic sizes of the nanotubes. ${ }^{14}$ It should be noted that the fits of the scattering curves for PEG2k provided a radius of gyration of $1.5 \mathrm{~nm}$ with and without $\mathrm{Ge}-$ DWINTs in agreement with the thermodynamic prediction of negligible interactions in this case. 
Therefore, we should expect different rheological and colloidal behaviors for these systems. In particular, depletion processes can play a role for PEG2k/Ge-DWINTs and steric colloidal stabilization for PEG20k/Ge-DWINTs (as a consequence of the large amount of polymer adsorbed onto Ge-DWINTs surfaces).

We investigated the flow properties of PEGs/Ge-DWINTs complexes (PEG2k and PEG20k) prepared at a fixed $R_{\text {PINTs }}=10$ while varying the concentration of imogolite nanotubes $\left(\mathrm{C}_{\mathrm{INTS}}\right)$. In this case, the fraction of polymer adsorbed onto Ge-DWINTs is the same whatever the value of $\mathrm{C}_{\mathrm{INT}}$ but varies by a factor of 2 between the two series (Figure 3 ). This should allow us to probe how the difference in amount of PEG adsorbed onto the nanotube surface impact the viscosity of the suspensions. The flow curves (viscosity $\eta v s$. shear stress $\sigma$ ) exhibit a shear thinning behavior whatever the molecular weight or the nanotube concentration (Figure 5a,b). With increasing shear stress, hydrodynamic interactions tend to overcome electrostatic interaction between PEGs/Ge-DWINTs complexes that end up aligning in the flow. To go further, we reproduced flow curves by adjusting a viscosity model based on the Quemada's approach: ${ }^{55,56}$

$$
\begin{array}{r}
\eta(\sigma)=\eta_{\infty}\left(\frac{1+\sigma / \sigma_{c}}{\chi+\sigma / \sigma_{c}}\right)^{2} \\
-1 \leq \chi \leq 1 \quad(7 \mathrm{~b})
\end{array}
$$

where $\eta_{\infty}$ represents the viscosity for infinite shear stress and $\sigma_{\mathrm{c}}$ is a critical shear stress. Its value is close to $\sigma$ when hydrodynamics effects are comparable to Brownian and interaction energies. $\chi$ is positive when a viscosity plateau at 0 -shear is measured while it is negative when a yield stress $\sigma_{y}$ occurs in the dispersion such as: $\sigma_{y}=-\chi \sigma_{c}$. By adjusting eq. $7 \mathrm{a}$ using the least- 
square method, fair agreement was obtained between experimental and calculated flow curves for both PEG2k and 20k/Ge-DWINTs complexes (Figure 5a,b). The evolution of yield stress $\sigma_{y}$ with Ge-DWINTs concentration depending the PEG molecular weight is represented in Figure 5c. The yield stress remains the same for low Ge-DWINTs concentrations but starts to increase when $\mathrm{C}_{\mathrm{INTs}}$ is above $3 \mathrm{~g} \cdot \mathrm{L}^{-1}$. 

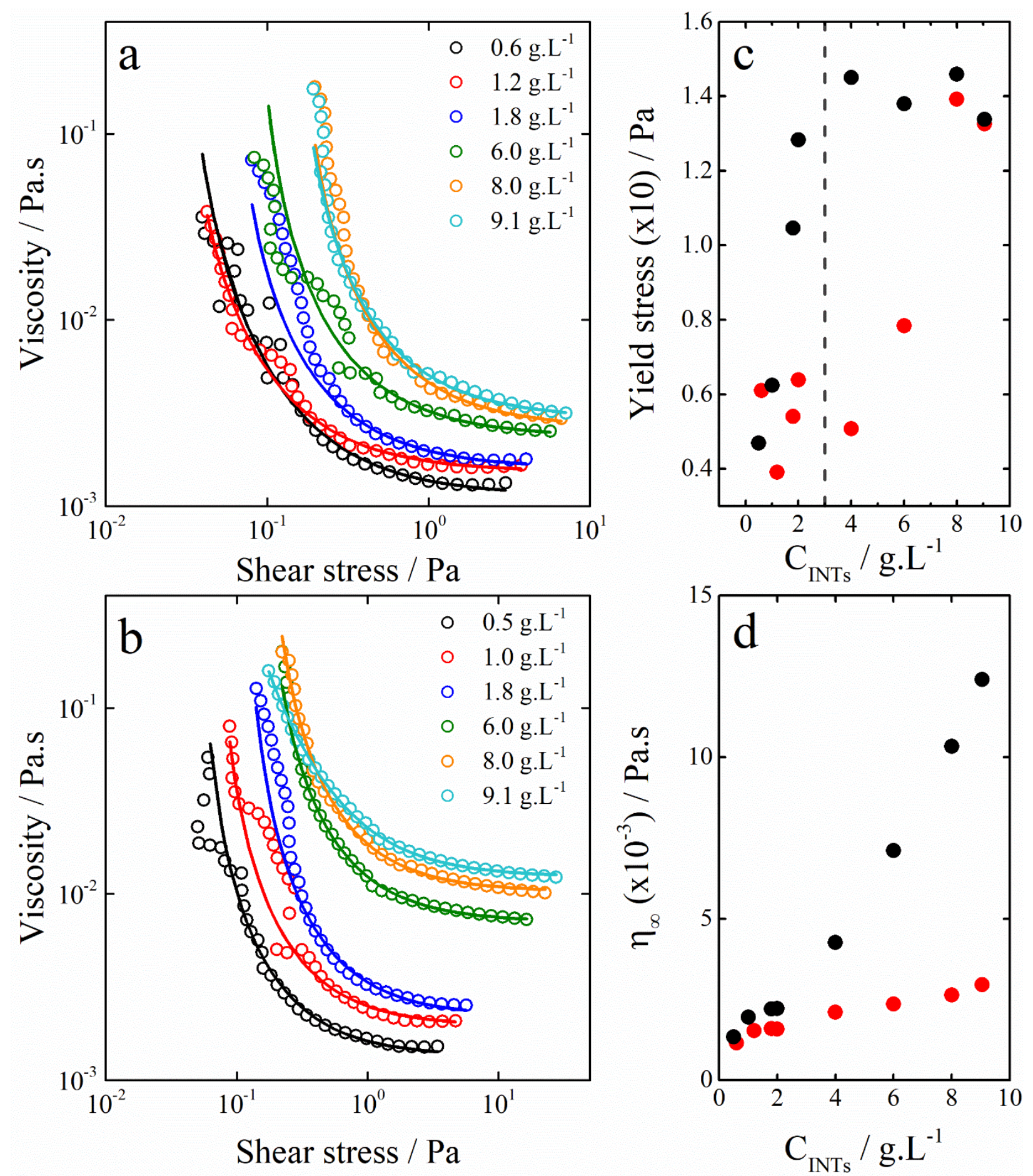

Figure 5. Flow curves for PEGs/imogolite mixtures prepared at different $\mathrm{C}_{\mathrm{INTs}}$ and PEGs molecular weight: (a) $\mathrm{M}_{\mathrm{w}}=2000 \mathrm{~g} \cdot \mathrm{mol}^{-1}$ and (b) $\mathrm{M}_{\mathrm{w}}=20000 \mathrm{~g} \cdot \mathrm{mol}^{-1}$. Continuous lines 
correspond to the best fit of eq. [7a]. Evolution of (c) yield stress and (d) infinite viscosity values with imogolite concentration for PEG2k (red) and PEG20k (black).

For the longest PEG chain, we observed a sharp increase of the yield stress right from the first concentrations investigated until reaching a constant value around $0.15 \mathrm{~Pa}$. This difference is directly related to the larger amount of PEG adsorbed on the imogolite surface for PEG20k and the modification of the polymer conformation. This is particularly noticeable when looking at the evolution of infinite shear viscosity (Figure 5d). An almost linear increase is observed with varying the imogolite concentration but the values are always lower for PEG2k compared to PEG20k. Bridging interactions between the nanotubes seems unlikely since the average distance is at least higher than $60 \mathrm{~nm}$ for the most concentrated suspension $\left(\sim 9 \mathrm{~g} \cdot \mathrm{L}^{-1}\right)$ that is $\sim 14$ times the average diameter of the nanotubes. ${ }^{24,25} \mathrm{PEG} / \mathrm{INT}$ mixtures rather look like a "decorated" nanotube with more or less amount of polymer as sketched in Figure 4. For PEG20k, steric interactions between the polymer and the nanotubes may form PEG/Ge-DWINTs complexes that are larger than the nanotubes themselves, which interfere more significantly thus raising the viscosity when shearing.

\section{CONCLUSIONS}

In summary, we investigated the adsorption mechanism of non-ionic polymers onto geo-inspired inorganic nanotubes in aqueous dispersions. Modeling nano-ITC measurements allowed us to quantify the standard variation of enthalpy, entropy and free energy during the adsorption of PEGs. Their affinity with the nanotube surface is dominated by favorable enthalpic contribution. We also evidenced that the adsorption mechanism depends on the length of the polymer molecular weight. Within the investigated polymer/Ge-DWINTs range, we estimated that more than $95 \%$ of polymer is adsorbed with the longest chain (PEG20k) against $40 \%$ for a 10 -fold 
lower polymer molecular weight. The role played by the molecular weight on the adsorption of PEG drastically impacts the high shear flow properties of the resulting complexes due to different interaction and conformation of the polymer coil at the interface with the nanotubes. These findings will open a fresh look on fundamental understanding of polymers with these modeled nanotubes but will also aid in an improved rational design of hybrid polymer/imogolite mixtures during the elaboration of nanocomposites.

\section{ASSOCIATED CONTENT}

Supporting Information. Details on the ITC data analysis and additional SANS data of GeDWINTs dispersion. This material is available free of charge via the Internet at http://pubs.acs.org.

\section{AUTHOR INFORMATION}

\section{Corresponding Author}

*E-mail: giuseppe.lazzara@unipa.it. Phone: +39 09123897962

*E-mail: erwan-nicolas.paineau@ universite-paris-saclay.fr. Phone: +33 (0) 169156051.

\section{Funding Sources}

Laboratoire Rhéologie et Procédés is part of LabEx Tec21 (Investissements d'Avenir - grant agreement no. ANR-11-LABX-0030), PolyNat Carnot Institut (Investissements d'Avenir - grant agreement \#ANR-16-CARN-0025-01) and Glyco@Alps programme (Investissements d'Avenir grant agreement \#ANR-15-IDEX-02). G.L. and G.C. thank the University of Palermo for financial Support (FFR2020).

\section{Notes}


The authors declare no competing financial interest.

\section{ACKNOWLEDGMENT}

The present work has benefited from Imagerie-Gif core facility supported by l'Agence Nationale de la Recherche (ANR-11-EQPX-0029/Morphoscope; ANR-10-INBS-04/FranceBioImaging; ANR-11-IDEX-0003-02/Saclay Plant Sciences). SANS data (https://doi.ill.fr/10.5291/ILLDATA.9-12-557) using D11 at Institut Laue Langevin took place with the approved proposal 912-557. The Partnership for Soft Condensed Matter (PSCM) is acknowledged for provided the laboratory infrastructure for sample preparation and pre-characterization.

\section{REFERENCES}

(1) Dahlgren, R.; Shoji, S.; Nanzyo, M. Mineralogical Characteristics of Volcanic Ash Soils. In Developments in Soil Science; Elsevier, 1993; Vol. 21, pp 101-143.

(2) Joussein, E.; Petit, S.; Churchman, J.; Theng, B.; Righi, D.; Delvaux, B. Halloysite Clay Minerals-a Review. Clay Miner. 2005, 40, 383-426.

(3) Farmer, V.; Fraser, A.; Tait, J. Synthesis of Imogolite - Tubular Aluminum Silicate Polymer. J. Chem. Soc.-Chem. Commun. 1977, No. 13, 462-463.

(4) Paineau, E. Imogolite Nanotubes: A Flexible Nanoplatform with Multipurpose Applications. Appl. Sci. 2018, 8 (10), 1921.

(5) Cradwick, P. D. G.; Wada, K.; Russell, J.; Yoshinaga, N.; Masson, C.; Farmer, V. Imogolite, a Hydrated Aluminum Silicate of Tubular Structure. Nat.-Phys. Sci. 1972, 240 (104), 187-189.

(6) Mukherjee, S.; Kim, K.; Nair, S. Short, Highly Ordered, Single-Walled Mixed-Oxide Nanotubes Assemble from Amorphous Nanoparticles. J. Am. Chem. Soc. 2007, 129 (21), 6820-6826.

(7) Thill, A.; Guiose, B.; Bacia-Verloop, M.; Geertsen, V.; Belloni, L. How the Diameter and Structure of $(\mathrm{OH})(3) \mathrm{Al} 2 \mathrm{O} 3 \mathrm{SixGe} 1-\mathrm{XOH}$ Imogolite Nanotubes Are Controlled by an Adhesion versus Curvature Cornpetition. J. Phys. Chem. C 2012, 116 (51), 26841-26849.

(8) Thill, A.; Maillet, P.; Guiose, B.; Spalla, O.; Belloni, L.; Chaurand, P.; Auffan, M.; Olivi, L.; Rose, J. Physico-Chemical Control over the Single- or Double-Wall Structure of Aluminogermanate Imogolite-like Nanotubes. J. Am. Chem. Soc. 2012, 134, 3780-3786.

(9) Kang, D.-Y.; Brunelli, N. A.; Yucelen, G. I.; Venkatasubramanian, A.; Zang, J.; Leisen, J.; Hesketh, P. J.; Jones, C. W.; Nair, S. Direct Synthesis of Single-Walled Aminoaluminosilicate Nanotubes with Enhanced Molecular Adsorption Selectivity. Nat. Commun. 2014, 5, 3342.

(10) Amara, M. S.; Paineau, E.; Rouziere, S.; Guiose, B.; Krapf, M.-E. M.; Tache, O.; Launois, P.; Thill, A. Hybrid, Tunable-Diameter, Metal Oxide Nanotubes for Trapping of Organic Molecules. Chem. Mater. 2015, 27 (5), 1488-1494. 
(11) Picot, P.; Gobeaux, F.; Coradin, T.; Thill, A. Dual Internal Functionalization of Imogolite Nanotubes as Evidenced by Optical Properties of Nile Red. Appl. Clay Sci. 2019, 178, 105133.

(12) Lisuzzo, L.; Cavallaro, G.; Lazzara, G.; Milioto, S.; Parisi, F.; Stetsyshyn, Y. Stability of Halloysite, Imogolite, and Boron Nitride Nanotubes in Solvent Media. Appl. Sci. 2018, 8 (7), 1068.

(13) Paineau, E.; Monet, G.; Peyre, V.; Goldmann, C.; Rouzière, S.; Launois, P. Colloidal Stability of Imogolite Nanotube Dispersions: A Phase Diagram Study. Langmuir 2019, 35 (38), 12451-12459.

(14) Paineau, E.; Rouzière, S.; Monet, G.; Diogo, C. C.; Morfin, I.; Launois, P. Role of Initial Precursors on the Liquid-Crystalline Phase Behavior of Synthetic Aluminogermanate Imogolite Nanotubes. J. Colloid Interface Sci. 2020, 580, 275-285.

(15) Kang, D.-Y.; Lydon, M. E.; Yucelen, G. I.; Jones, C. W.; Nair, S. Solution-Processed Ultrathin Aluminosilicate Nanotube-Poly(Vinyl Alcohol) Composite Membranes with Partial Alignment of Nanotubes. Chemnanomat 2015, 1 (2), 102-108.

(16) Fernandez-Martinez, A.; Tao, J.; Wallace, A. F.; Bourg, I. C.; Johnson, M. R.; De Yoreo, J. J.; Sposito, G.; Cuello, G. J.; Charlet, L. Curvature-Induced Hydrophobicity at Imogolitewater Interfaces. Environ. Sci. Nano 2020, 7 (9), 2759-2772.

(17) Nasi, R.; Sannino, F.; Picot, P.; Thill, A.; Oliviero, O.; Esposito, S.; Armandi, M.; Bonelli, B. Hybrid Organic-Inorganic Nanotubes Effectively Adsorb Some Organic Pollutants in Aqueous Phase. Appl. Clay Sci. 2020, 186, 105449.

(18) Monet, G.; Paineau, E.; Chai, Z.; Amara, M. S.; Orecchini, A.; Jiménez-Ruiz, M.; RuizCaridad, A.; Fine, L.; Rouzière, S.; Liu, L.-M.; Teobaldi, G.; Rols, S.; Launois, P. Solid Wetting-Layers in Inorganic Nano-Reactors: The Water in Imogolite Nanotube Case. Nanoscale Adv. 2020, 2 (5), 1869-1877.

(19) Poli, E.; Elliott, J. D.; Ratcliff, L. E.; Andrinopoulos, L.; Dziedzic, J.; Hine, N. D. M.; Mostofi, A. A.; Skylaris, C.-K.; Haynes, P. D.; Teobaldi, G. The Potential of Imogolite Nanotubes as (Co-)Photocatalysts: A Linear-Scaling Density Functional Theory Study. $J$. Phys.-Condens. Matter 2016, 28 (7), 074003.

(20) Elliott, J. D.; Poli, E.; Scivetti, I.; Ratcliff, L. E.; Andrinopoulos, L.; Dziedzic, J.; Hine, N. D. M.; Mostofi, A. A.; Skylaris, C.-K.; Haynes, P. D.; Teobaldi, G. Chemically Selective Alternatives to Photoferroelectrics for Polarization-Enhanced Photocatalysis: The Untapped Potential of Hybrid Inorganic Nanotubes. Adv. Sci. 2017, 4 (2), 1600153.

(21) Olson, N.; Deshpande, N.; Gunduz, S.; Ozkan, U. S.; Brunelli, N. A. Utilizing Imogolite Nanotubes as a Tunable Catalytic Material for the Selective Isomerization of Glucose to Fructose. Catal. Today 2019, 323, 69-75.

(22) Poli, E.; Elliott, J.; Chulkov, S. K.; Watkins, M. B.; Teobaldi, G. The Role of CationVacancies for the Electronic and Optical Properties of Aluminosilicate Imogolite Nanotubes: A Non-Local, Linear-Response TDDFT Study. Front. Chem. 2019, 7, 210.

(23) Li, J.; Jiménez-Calvo, P.; Paineau, E.; Ghazzal, M. N. Metal Chalcogenides Based Heterojunctions and Novel Nanostructures for Photocatalytic Hydrogen Evolution. Catalysts 2020, 10 (1), 89.

(24) Paineau, E.; Krapf, M.-E. M.; Amara, M.-S.; Matskova, N. V.; Dozov, I.; Rouziere, S.; Thill, A.; Launois, P.; Davidson, P. A Liquid-Crystalline Hexagonal Columnar Phase in Highly-Dilute Suspensions of Imogolite Nanotubes. Nat. Commun. 2016, 7, 10271. 
(25) Paineau, E.; Launois, P. Influence of the Al/Ge Ratio on the Structure and SelfOrganization of Anisometric Imogolite Nanotubes. Crystals 2020, 10 (12), 1094.

(26) Poli, E.; Elliott, J. D.; Chai, Z.; Teobaldi, G. Termination Effects in Aluminosilicate and Aluminogermanate Imogolite Nanotubes: A Density Functional Theory Study. Crystals 2020, 10 (11), 1051.

(27) Park, K.-L.; Ma, W.; Higaki, Y.; Takahara, A. Design and Characterization of Hybrid Hydrogels Composed of Imogolite Fibrous Nanotubular Clay and Hyaluronic Acid. Polymer 2016, 100, 238-243.

(28) Shikinaka, K. Design of Stimuli-Responsive Materials Consisting of the Rigid Cylindrical Inorganic Polymer "Imogolite." Polym. J. 2016, 48 (6), 689-696.

(29) Ryu, J.; Ko, J.; Lee, H.; Shin, T.-G.; Sohn, D. Structural Response of ImogolitePoly(Acrylic Acid) Hydrogel under Deformation. Macromolecules 2016, 49 (5), 18731881.

(30) Su, C.-Y.; Yang, A.-C.; Jiang, J.-S.; Yang, Z.-H.; Huang, Y.-S.; Kang, D.-Y.; Hua, C.-C. Properties of Single-Walled Aluminosilicate Nanotube/Poly (Vinyl Alcohol) Aqueous Dispersions. J. Phys. Chem. B 2018, 122 (1), 380-391.

(31) Li, M.; Brant, J. A. Effects of Aluminogermanate Imogolite Nanotube Orientation on Mass Transport across Polyamide Nanocomposite Membranes. J. Membr. Sci. 2019, 585, 38-51.

(32) Lee, W. J.; Paineau, E.; Anthony, D. B.; Gao, Y.; Leese, H. S.; Rouzière, S.; Launois, P.; Shaffer, M. S. P. Inorganic Nanotube Mesophases Enable Strong Self-Healing Fibers. ACS Nano 2020, 14, 5570-5580.

(33) Li, L.; Takada, A.; Ma, W.; Fujikawa, S.; Ariyoshi, M.; Igata, K.; Okajima, M.; Kaneko, T.; Takahara, A. Structure and Properties of Hybrid Film Fabricated by Spin-Assisted Layerby-Layer Assembly of Sacran and Imogolite Nanotubes. Langmuir 2020, 36 (7), 17181726.

(34) Mukai, M.; Takahara, M.; Takada, A.; Takahara, A. Preparation of an (Inorganic/Organic) Hybrid Hydrogel from a Peptide Oligomer and a Tubular Aluminosilicate Nanofiber. RSC Adv. 2021, 11 (9), 4901-4905.

(35) Bonini, M.; Gabbani, A.; Del Buffa, S.; Ridi, F.; Baglioni, P.; Bordes, R.; Holmberg, K. Adsorption of Amino Acids and Glutamic Acid-Based Surfactants on Imogolite Clays. Langmuir 2017, 33 (9), 2411-2419.

(36) Kang, D.-Y.; Tong, H. M.; Zang, J.; Choudhury, R. P.; Sholl, D. S.; Beckham, H. W.; Jones, C. W.; Nair, S. Single-Walled Aluminosilicate Nanotube/Poly(Vinyl Alcohol) Nanocomposite Membranes. Acs Appl. Mater. Interfaces 2012, 4 (2), 965-976.

(37) Lange, T.; Charpentier, T.; Gobeaux, F.; Charton, S.; Testard, F.; Thill, A. Partial Transformation of Imogolite by Decylphosphonic Acid Yields an Interface Active Composite Material. Langmuir 2019, 35 (11), 4068-4076.

(38) Bertolino, V.; Cavallaro, G.; Lazzara, G.; Milioto, S.; Parisi, F. Biopolymer-Targeted Adsorption onto Halloysite Nanotubes in Aqueous Media. Langmuir 2017, 33 (13), 33173323.

(39) Archer, W. R.; Schulz, M. D. Isothermal Titration Calorimetry: Practical Approaches and Current Applications in Soft Matter. Soft Matter 2020, 16, 8760-8774.

(40) Cavallaro, G.; Lazzara, G.; Milioto, S. Aqueous Phase/Nanoparticles Interface: Hydroxypropyl Cellulose Adsorption and Desorption Triggered by Temperature and Inorganic Salts. Soft Matter 2012, 8 (13), 3627-3633. 
(41) Holtzer, A.; Holtzer, M. F. Use of the van't Hoff Relation in Determination of the Enthalpy of Micelle Formation. J. Phys. Chem. 1974, 78 (14), 1442-1443.

(42) Cavallaro, G.; Donato, D. I.; Lazzara, G.; Milioto, S. Films of Halloysite Nanotubes Sandwiched between Two Layers of Biopolymer: From the Morphology to the Dielectric, Thermal, Transparency, and Wettability Properties. J. Phys. Chem. C 2011, 115 (42), 20491-20498.

(43) Chiu, C.-W.; Lin, J.-J. Self-Assembly Behavior of Polymer-Assisted Clays. Prog. Polym. Sci. 2012,37 (3), 406-444.

(44) El Rifaii, K.; Wensink, H. H.; Bizien, T.; Gabriel, J.-C. P.; Michot, L.; Davidson, P. Destabilization of the Nematic Phase of Clay Nanosheet Suspensions by Polymer Adsorption. Langmuir 2020, 36, 12563-12571.

(45) Amara, M.-S.; Paineau, E.; Bacia-Verloop, M.; Krapf, M.-E. M.; Davidson, P.; Belloni, L.; Levard, C.; Rose, J.; Launois, P.; Thill, A. Single-Step Formation of Micron Long $(\mathrm{OH}) 3 \mathrm{~A} 12 \mathrm{O} 3 \mathrm{Ge}(\mathrm{OH})$ Imogolite-like Nanotubes. Chem. Commun. 2013, 49 (96), 1128411286.

(46) Tellinghuisen, J. Calibration in Isothermal Titration Calorimetry: Heat and Cell Volume from Heat of Dilution of $\mathrm{NaCl}$ (Aq). Anal. Biochem. 2007, 360 (1), 47-55.

(47) Lieutenant, K.; Lindner, P.; Gahler, R. A New Design for the Standard Pinhole SmallAngle Neutron Scattering Instrument D11. J. Appl. Crystallogr. 2007, 40 (6), 1056-1063.

(48) Keiderling, U. The New 'BerSANS-PC'Software for Reduction and Treatment of Small Angle Neutron Scattering Data. Appl. Phys. A 2002, 74 (1), s1455-s1457.

(49) Breßler, I.; Kohlbrecher, J.; Thünemann, A. F. SASfit: A Tool for Small-Angle Scattering Data Analysis Using a Library of Analytical Expressions. J. Appl. Crystallogr. 2015, 48 (5), 1587-1598.

(50) Burchill, S.; Hall, P. L.; Harrison, R.; Hayes, M. H. B.; Langford, J. I.; Livingston, W. R.; Smedley, R. J.; Ross, D. K.; Tuck, J. J. Smectite-Polymer Interactions in Aqueous Systems. Clay Miner. 1983, 18 (4), 373-397.

(51) Luckham, P. F.; Rossi, S. The Colloidal and Rheological Properties of Bentonite Suspensions. Adv. Colloid Interface Sci. 1999, 82 (1-3), 43-92.

(52) Debye, P. Molecular-Weight Determination by Light Scattering. J. Phys. Chem. 1947, 51 (1), 18-32.

(53) Pedersen, J. S.; Sommer, C. Temperature Dependence of the Virial Coefficients and the Chi Parameter in Semi-Dilute Solutions of PEG. In Scattering Methods and the Properties of Polymer Materials; Springer, 2005; pp 70-78.

(54) De Lisi, R.; Lazzara, G.; Lombardo, R.; Milioto, S.; Muratore, N.; Liveri, M. T. Thermodynamic Behavior of Non-Ionic Tri-Block Copolymers in Water at Three Temperatures. J. Solut. Chem. 2006, 35 (5), 659-678.

(55) Baravian, C.; Vantelon, D.; Thomas, F. Rheological Determination of Interaction Potential Energy for Aqueous Clay Suspensions. Langmuir 2003, 19 (19), 8109-8114.

(56) Paineau, E.; Michot, L. J.; Bihannic, I.; Baravian, C. Aqueous Suspensions of Natural Swelling Clay Minerals. 2. Rheological Characterization. Langmuir 2011, 27 (12), 78067819. 


\section{TOC Graphic}

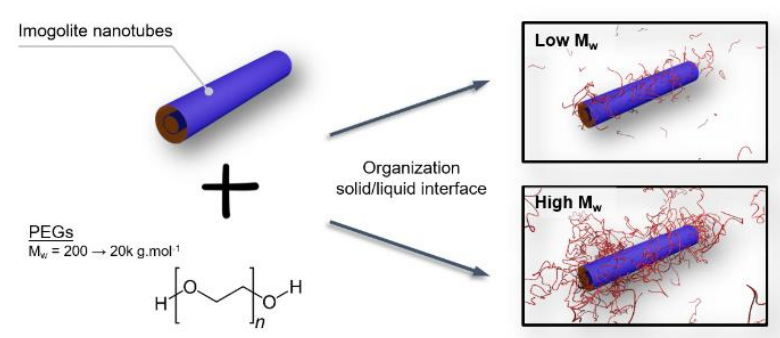

